\title{
SNAPSHOT
}

\section{Chasing ice}

Taking photographs of retreating glaciers is not an easy task. The conditions are by definition cold, and the ground from which a good view can be seen is often soft, causing tripods to slump over the years needed to watch the glacial creep.

National Geographic photographer James Balog decided to tackle this challenge head on, founding the Extreme Ice Survey in 2007. His project focuses high-resolution time-lapse photography cameras on remote glaciers to get a detailed picture of their movement. A documentary film about the effort, Chasing Ice, premiered at the Sundance Film Festival in Park City, Utah, in January.

The project, which is ongoing, placed more than 30 cameras on 15 glaciers in Greenland, Iceland, Alaska, Canada, the Nepalese Himalaya and the US Rocky Mountains, taking photographs up to every half hour in daylight.

The team also took repeat shots at locations in Iceland, Bolivia, British Columbia in Canada, and the French and Swiss Alps.

Balog had to design and build his cameras himself, adapting them to withstand temperatures down to $-40^{\circ} \mathrm{C}$, deep snow, rain, rockfall and winds of

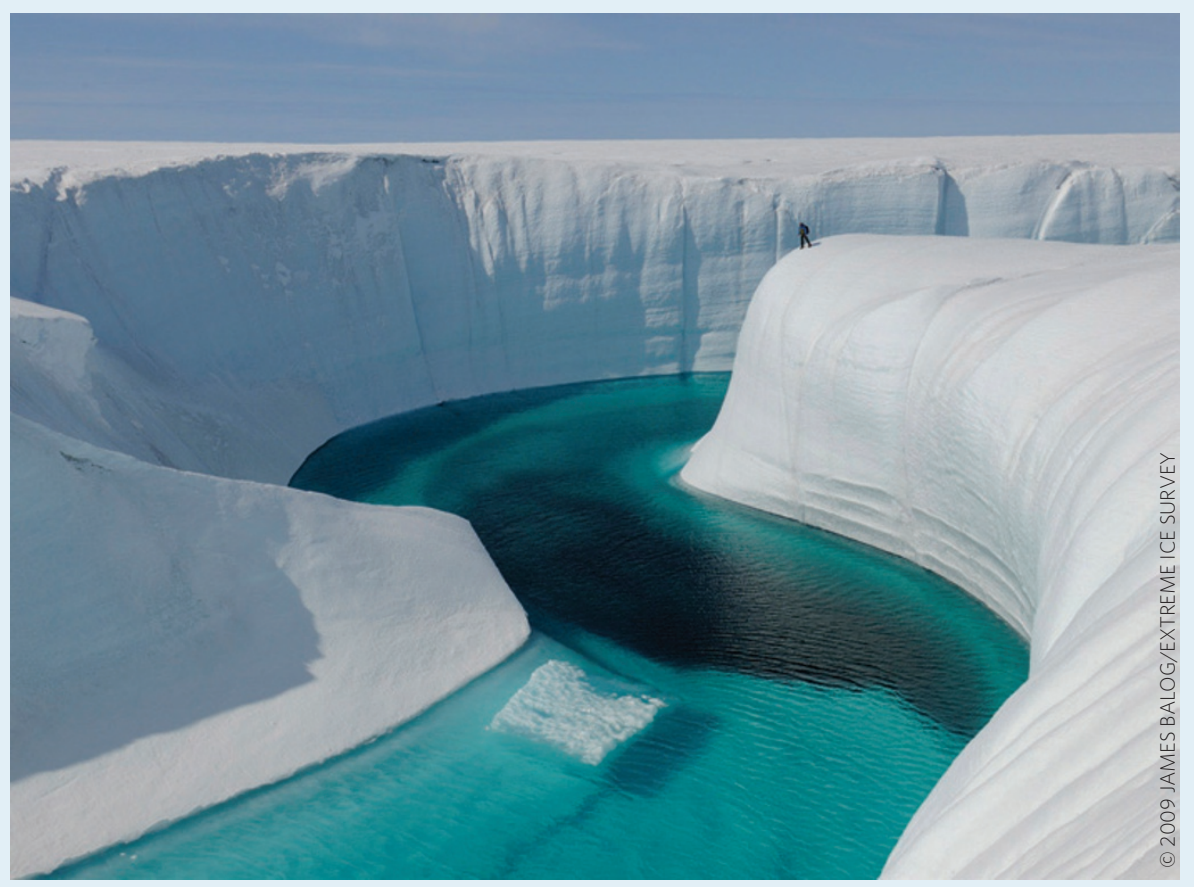

up to $250 \mathrm{~km} \mathrm{~h}^{-1}$. The resulting cameras, complete with solar-panel power, backup batteries and anchoring systems to attach them to rock, weigh more than $45 \mathrm{~kg}$. The survey team couldn't always rely on helicopters to transport them to their destination; they also trekked to remote locations by horseback, dogsled and ski. Balog spent six months designing workable systems. "Those six months were the hardest of my career," says Balog. "I spent half my life at the local hardware store."

The Extreme Ice Survey includes research partners Jason Box from the Ohio State University Byrd Polar Research Center, Daniel Fagre with the US Geological Survey in Glacier National Park, Montana, and Tad Pfeffer of the University of Colorado. For Balog, the point of the project is both to collect good scientific data and to communicate the issues of glacial retreat to the public using stunning artwork. "Most of the time, art and science stare at each other across a gulf of mutual incomprehension. The Extreme Ice Survey is dedicated to merging those two parts of human understanding," writes Balog on the survey's website.

These high-definition time-lapsed photographs of remote glaciers also have research value, helping plug holes in the

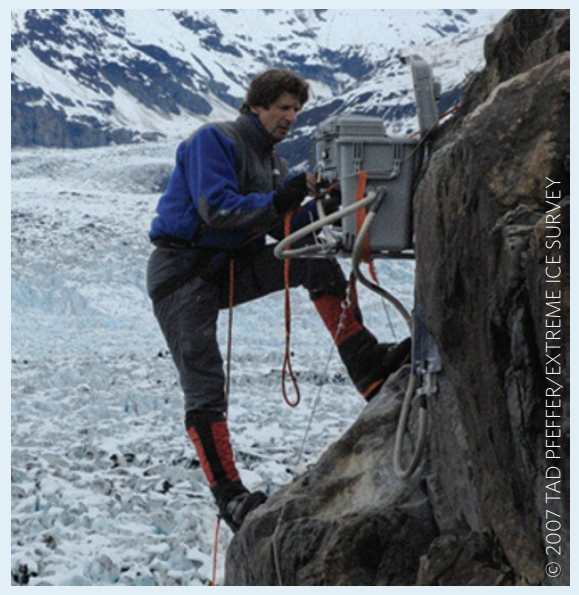

data. "Remote sensing has a lot of gaps because of clouds," says Fagre. "A lot of these glaciers are observed at most once a year. Now you can see exactly what's going on for a whole annual cycle." Time-lapse photography of glaciers isn't new, notes Fagre. It has been done for famous glaciers in Switzerland, for example, for quite some time. What's new here is the global scope of the project and the high resolution of the images, he says.

The effort complements work being done elsewhere. The World Glacier Monitoring Service, started in 1894, holds 36,000 observations about glacial length changes for 1,800 glaciers, and roughly 3,400 mass-balance measurements for 230 glaciers. It continues to compile a detailed inventory of more than 100,000 glaciers, mostly using satellite images. Projects such as the Extreme Ice Survey "cannot directly be linked to the longterm monitoring programmes," says Michael Zemp, director of that service at the University of Zurich, because their time and resolution parameters are different. "However, these [Extreme Ice Survey] series certainly have a great potential for model validation and for helping a wider public visualize glacier processes," he says.

The Extreme Ice Survey is also featured in a Google Earth application, and a photographic book, Ice: Portraits of the World's Vanishing Glaciers, will be released later this year. 